\title{
Vaginal Biopsy
}

National Cancer Institute

\section{Source}

National Cancer Institute. Vaginal Biopsy. NCI Thesaurus. Code C51595.

Removal of tissue from the vagina for microscopic examination. 